\title{
Author Correction: c-Rel orchestrates energy-dependent epithelial and macrophage reprogramming in fibrosis
}

Jack Leslie (D), Marina García Macia (D), Saimir Luli, Julie C. Worrell D, William J. Reilly, Hannah L. Paish, Amber Knox, Ben S. Barksby, Lucy M. Gee, Marco Y. W. Zaki DD, Amy L. Collins (D, Rachel A. Burgoyne, Rainie Cameron, Charlotte Bragg, Xin Xu, Git W. Chung, Colin D. A. Brown, Andrew D. Blanchard, Carmel B. Nanthakumar, Morten Karsdal, Stuart M. Robinson, Derek M. Manas, Gourab Sen, Jeremy French, Steven A. White, Sandra Murphy 1 , Matthias Trost (D), Johannes L. Zakrzewski, Ulf Klein (D), Robert F. Schwabe, Ingmar Mederacke (D), Colin Nixon (D), Tom Bird (D), Laure-Anne Teuwen, Luc Schoonjans, Peter Carmeliet (D), Jelena Mann, Andrew J. Fisher (iD, Neil S. Sheerin, Lee A. Borthwick, Derek A. Mann and Fiona Oakley iD

Correction to: Nature Metabolism https://doi.org/10.1038/s42255-020-00306-2, published online 9 November 2020.

In the version of this article initially published, in the $\times 40$ diseased human kidney images in Supplementary Fig. 1, the FSGS image duplicated the DN image. The error has been corrected in the HTML version of the article. 


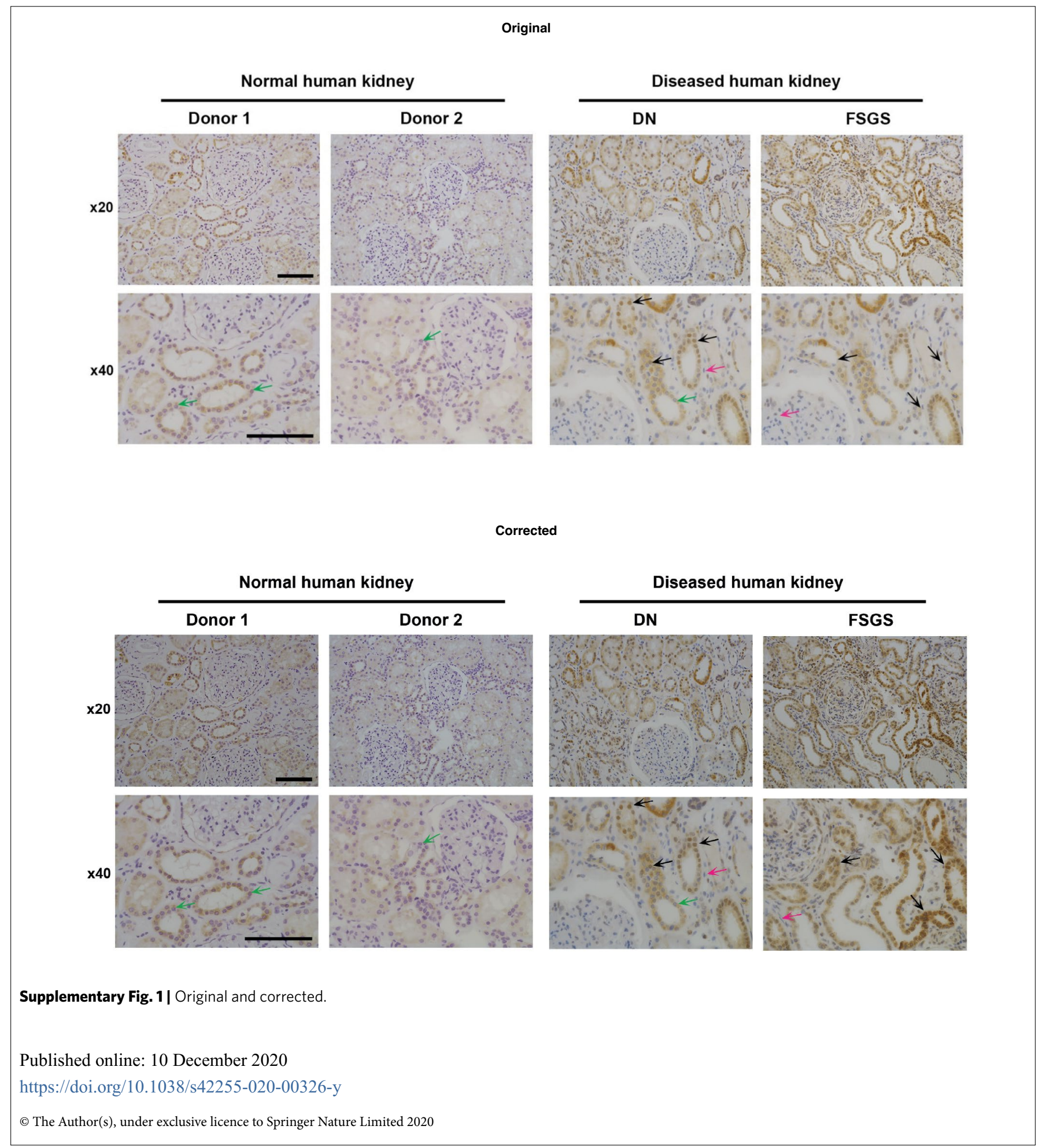

